\title{
INTERVENÇÃO EM ORIENTAÇÃO PROFISSIONAL EM ESTUDANTES DE ESCOLAS PÚBLICAS BRASILEIRAS: UMA REVISÃO NARRATIVA
}

Bruna Pessenda

Universidade Estadual Paulista "Júlio de Mesquita Filho" (UNESP)

Thais de Souza Mascotti

Universidade Estadual Paulista "Júlio de Mesquita Filho" (UNESP)

Hugo Ferrari Cardoso

Universidade Estadual Paulista "Júlio de Mesquita Filho" (UNESP)

\begin{abstract}
Resumo
Programas de intervenção em Orientação Profissional (OP) nas escolas públicas podem fornecer oportunidades de os estudantes discutirem sobre a sociedade, o mundo do trabalho e os significados da escolha profissional, o que possivelmente os prepararia para uma entrada mais crítica e consciente no mundo do trabalho. Assim, este estudo visou realizar uma revisão narrativa de artigos nacionais voltados para grupos de intervenção em OP. Para tanto, foi pesquisado em duas bases de dados (Pepsic e Scielo) as palavras-chave "orientação profissional" e "orientação vocacional". O critério de seleção para análise dos artigos foi que contivessem intervenções em OP em alunos matriculados no ensino regular de escolas públicas. Foram encontrados apenas três artigos nas bases de dados pesquisadas, mostrando que se tem a necessidade de mais pesquisas, teorias e modelos que correspondam à realidade de escolas públicas, uma vez que tais pesquisas poderiam apontar novos rumos a serem tomados pela OP.
\end{abstract}

Palavras-chave: orientação profissional; intervenção; estudantes.

\section{INTERVENTION IN VOCATIONAL GUIDANCE IN STUDENTS OF BRAZILIAN PUBLIC SCHOOLS: A NARRATIVE REVIEW}

\begin{abstract}
Intervention programs in Vocational Guidance in public schools can provide opportunities for students to discuss society, the world of work and the meanings of professional choice, which would possibly prepare them for a more critical and conscious entry into the world of work. Thus, this study aimed to conduct a narrative review of national articles aimed at intervention groups in vocational guidance. To do so, the keywords "orientação profissional" and "orientação vocacional" were searched in two databases (Pepsic and Scielo). The selection criterion for the analysis of the articles was that they contained interventions in vocational guidance in students enrolled in the regular teaching of public schools. Only three articles were found in the databases researched, showing that there is a need for more research, theories and models that correspond to the reality of public schools, since such research could point out new directions to be taken by the OP.
\end{abstract}

Keywords: professional orientation; intervention; students. 


\title{
LA INTERVENCIÓN EN ORIENTACIÓN PROFESIONAL EN LOS ESTUDIANTES DE LAS ESCUELAS PÚBLICAS BRASILEÑAS: UNA REVISIÓN NARRATIVA
}

\begin{abstract}
Resumen
Los programas de intervención en orientación profesional (OP) en las escuelas públicas pueden proporcionar oportunidades para que los estudiantes discuten acerca de la sociedad, el mundo del trabajo y de los significados de la elección profesional, que posiblemente no prepararlos para una entrada más crítica y consciente en el mundo del trabajo. Este estudio tuvo como objetivo llevar a cabo una revisión narrativa de los artículos nacionales se enfrentan en los grupos de intervención OP. Por lo tanto, se investigó en dos bases de datos (Pepsic y Scielo) Palabras clave "orientação profissional" y "orientação vocacional". Los criterios de selección para el análisis de los artículos que se encuentran en las intervenciones en OP en los estudiantes matriculados en la enseñanza regular en las escuelas públicas. Sólo tres artículos fueron encontrados en las bases de datos de la encuesta, lo que demuestra que usted tiene la necesidad de más investigación, teorías y modelos que corresponden a la realidad de las escuelas públicas, ya que este tipo de investigación podría apuntar a nuevas direcciones a tomar por el OP.

Palabras clave: orientación profesional; intervención; estudiantes.
\end{abstract}

\section{INTRODUÇÃO}

A origem da Orientação Profissional (OP) remete ao início do século $X X$, na Europa, com a criação do Centro de Orientação Profissional de Munique. Seu objetivo inicial consistia basicamente em detectar, na indústria, trabalhadores inaptos para a realização de determinadas tarefas e evitar acidentes de trabalho. Entretanto, seu marco oficial dá-se com a criação do primeiro Centro de Orientação Profissional norte-americano e a publicação do livro "Escolhendo uma Vocação" de Frank Parsons. Nessa época, os testes psicológicos eram utilizados para a definição das características individuais com a finalidade de combiná-las com as características e ambientes ocupacionais (Sparta, 2003).

De acordo com Lassance e Sparta (2003) e Bock (2002), com o declínio da sociedade industrial, um novo paradigma de OP surgiu, cujo foco deixou de ser a produção e passou a ser o indivíduo, sujeito de escolha. Assim, na sociedade pós-industrial, a OP passou a contribuir para promover uma reflexão crítica e ética sobre o compromisso social implicado nas escolhas profissionais dos indivíduos, assumindo um papel de agente de mudança associado com o desenvolvimento do próprio sujeito.

Dessa forma, a partir da década de 1940, o processo de orientação passou a não ser tão diretivo, o uso de testes psicológicos declinou e surgiram outras teorias sobre a escolha profissional. Nessas novas perspectivas em OP não havia uma preocupação em obter, ao término do processo, uma definição fechada de carreira a ser seguida pelo orientado, mas sim em aumentar seu autoconhecimento fazendo com que o mesmo refletisse, principalmente, acerca de suas condições, que favoreciam ou limitavam, quanto à realização de determinadas escolhas (tanto pessoais quanto profissionais). Atualmente, o trabalho de orientação ampliou-se significativamente e, o que antes se limitava a 
auxiliar pessoas em processo de inserção no mercado de trabalho, agora passa a abarcar reflexões sobre elaboração de projetos de vida (Sparta, 2003).

Considerando o contexto escolar, um dos papéis do orientador profissional seria contribuir com informações sobre o mercado de trabalho, de forma a auxiliar os jovens em momentos de conflito em relação à escolha profissional, ou seja, desde a inserção, até a participação na sociedade. Ações possíveis neste contexto estariam relacionadas à capacitação, promoção de discussões, reflexões, críticas a respeito da realidade do mundo e das circunstâncias de trabalho, bem como também incentivar esse público na busca de melhores condições para a sociedade (Faht, 2011). Em outras palavras, um dos objetivos seria a facilitação da aprendizagem e o desenvolvimento psicossocial dos alunos, de suas capacidades e interesses, favorecendo o autoconhecimento, estimulando a motivação e a construção de projetos de vida (Pocinho, Correia, Carvalho, \& Silva, 2010).

Assim, nesse contexto, faz-se importante orientar adequadamente os jovens no processo de escolha profissional, para que os mesmos possam estar preparados para a construção de estratégias que lhes permitam enfrentar criticamente as dificuldades e buscar novos caminhos na concretização de seus projetos de vida. Dessa forma, se realizada nas escolas com a proposta de discutir o mundo do trabalho, a OP pode ser uma das tentativas de conscientizar os jovens a respeito dos estereótipos e informações equivocadas sobre as profissões (Bastos, 2005; Ribeiro, 2003).

Todavia, de acordo com Lassance e Sparta (2003) e Aguiar e Conceição (2008), muitas vezes a OP acaba por servir mais a alunos de escolas particulares do que escolas públicas, uma vez que outros fatores interferem nas trajetórias educacionais e profissionais dos estudantes. Ainda de acordo com os mesmos autores, chegar ao terceiro ano do ensino médio com a perspectiva de realizar um ensino superior, em geral, é uma realidade de adolescentes urbanos de classe média e que muito difere da realidade em outros contextos onde a escassez de recursos, principalmente financeiros, é presente.

No Brasil, percebe-se a escassez de estudos em OP com o público de escolas públicas. Com o propósito de explorar a literatura da produção científica da área, foram realizadas buscas em bases de dados nacionais visando identificar trabalhos publicados na área de OP envolvendo escolas públicas. A Tabela 1 apresenta uma síntese das informações sobre os estudos encontradas. 
Tabela 1. Levantamento da produção brasileira de artigos que tiveram como objetivo a realização de análise da literatura nacional sobre OP.

\begin{tabular}{|c|c|c|c|}
\hline Autores & $\begin{array}{l}\text { Objetivo do } \\
\text { estudo }\end{array}$ & Período analisado & Variável escola \\
\hline $\begin{array}{c}\text { Noronha e Ambiel } \\
(2006)\end{array}$ & $\begin{array}{c}\text { Análise da } \\
\text { produção científica } \\
\text { nacional em OP }\end{array}$ & 1950 a 2000 & $\begin{array}{c}\text { Não apresenta a } \\
\text { análise em relação } \\
\text { ao tipo de escola }\end{array}$ \\
\hline $\begin{array}{c}\text { Teixeira, } \\
\text { Lassance, Silva e } \\
\text { Bardagi (2007) }\end{array}$ & $\begin{array}{c}\text { Análise da } \\
\text { produção científica } \\
\text { na Revista } \\
\text { Brasileira de } \\
\text { Orientação } \\
\text { Profissional }\end{array}$ & 1997 a 2006 & $\begin{array}{c}\text { Não apresenta a } \\
\text { análise em relação } \\
\text { ao tipo de escola }\end{array}$ \\
\hline Rueda (2009) & $\begin{array}{c}\text { Análise da } \\
\text { produção científica } \\
\text { na Revista } \\
\text { Brasileira de } \\
\text { Orientação } \\
\text { Profissional }\end{array}$ & 2003 a 2008 & $\begin{array}{c}\text { Não apresenta a } \\
\text { análise em relação } \\
\text { ao tipo de escola }\end{array}$ \\
\hline $\begin{array}{l}\text { Melo-Silva, Leal e } \\
\text { Fracalozzi (2010) }\end{array}$ & $\begin{array}{c}\text { Análise da } \\
\text { produção científica } \\
\text { em congressos } \\
\text { brasileiros de OP }\end{array}$ & 1999 e 2009 & $\begin{array}{c}\text { Não apresenta a } \\
\text { análise em relação } \\
\text { ao tipo de escola }\end{array}$ \\
\hline $\begin{array}{c}\text { Ambiel e Polli } \\
\text { (2011) }\end{array}$ & $\begin{array}{c}\text { Análise da } \\
\text { produção científica } \\
\text { de avaliação } \\
\text { psicológica em OP }\end{array}$ & 2000 a 2011 & $\begin{array}{c}\text { Não apresenta a } \\
\text { análise em relação } \\
\text { ao tipo de escola }\end{array}$ \\
\hline $\begin{array}{c}\text { Aguiar e } \\
\text { Conceição (2012) }\end{array}$ & $\begin{array}{c}\text { Análise da } \\
\text { produção científica } \\
\text { nacional em OP }\end{array}$ & 2006 a 2010 & $\begin{array}{c}\text { Não apresenta a } \\
\text { análise em relação } \\
\text { ao tipo de escola }\end{array}$ \\
\hline $\begin{array}{l}\text { Noronha et al. } \\
\text { (2014) }\end{array}$ & $\begin{array}{c}\text { Análise da } \\
\text { produção científica } \\
\text { na Revista } \\
\text { Brasileira de } \\
\text { Orientação } \\
\text { Profissional }\end{array}$ & 2007 a 2011 & $\begin{array}{c}\text { Não apresenta a } \\
\text { análise em relação } \\
\text { ao tipo de escola }\end{array}$ \\
\hline $\begin{array}{c}\text { Silva, Vieira, } \\
\text { Cardoso e Campos } \\
\text { (2015) }\end{array}$ & $\begin{array}{c}\text { Análise da } \\
\text { produção científica } \\
\text { nacional sobre OP } \\
\text { com o público } \\
\text { matriculado em }\end{array}$ & 2005 a 2014 & $\begin{array}{c}\text { Priorizou-se } \\
\text { instituições } \\
\text { públicas de ensino } \\
\text { (cursinhos } \\
\text { populares) }\end{array}$ \\
\hline
\end{tabular}




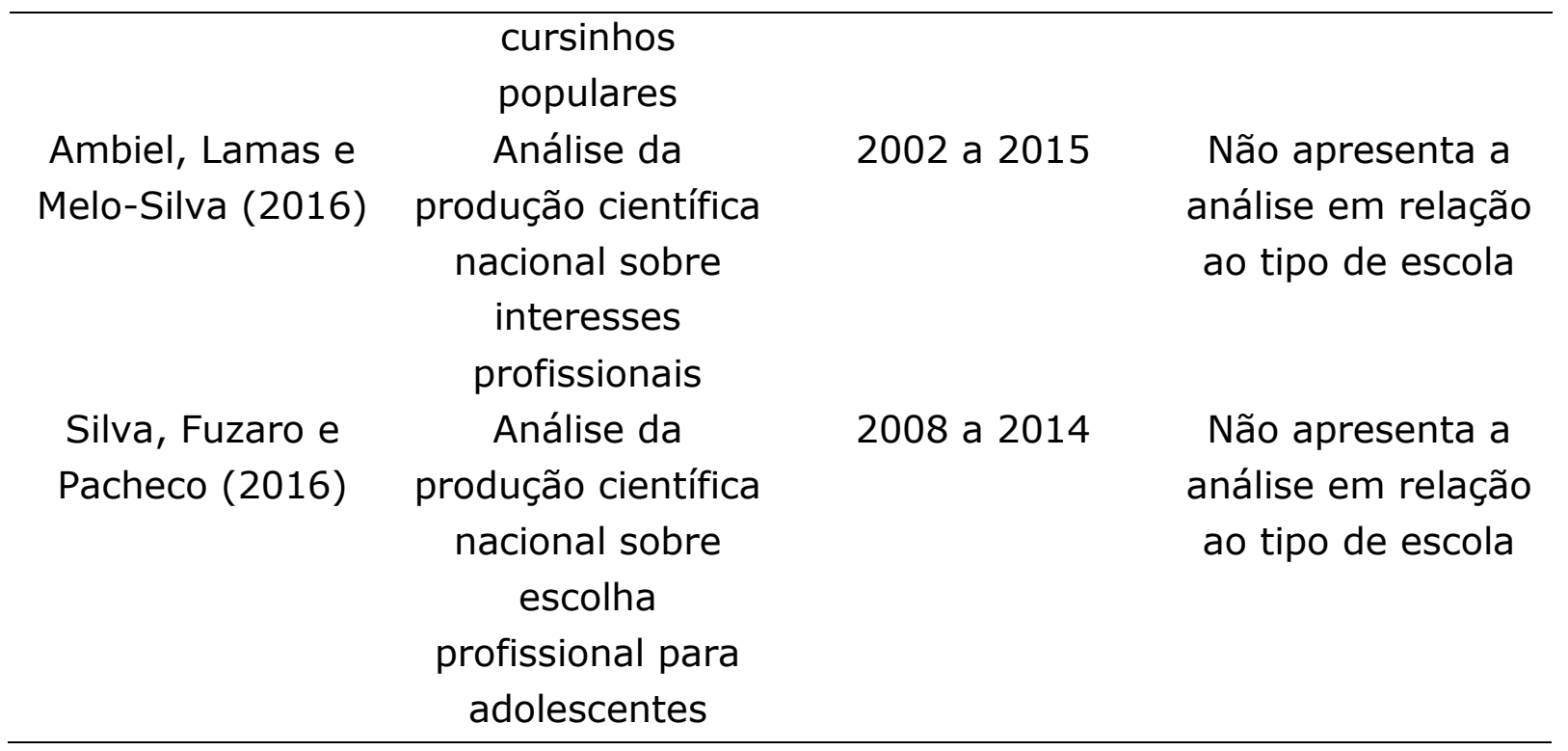

Por meio da Tabela 1 é possível constatar que, embora existam produções científicas nacionais que realizaram a análise da literatura sobre artigos da área de OP, poucos fizeram a análise levando em consideração o tipo de escola. Mais especificamente, embora um artigo tenha levado em consideração apenas o público de escolas públicas (Silva et al., 2015), o mesmo considerou na análise todos os artigos em que foram investigados alunos de cursinhos populares, não fazendo distinção se a publicação apresentava uma intervenção em OP ou outra forma de coleta de dados (por exemplo, aplicação de um único instrumento, questionário ou entrevista - o que não se configura como um processo de OP).

De acordo com Ribeiro e Melo-Silva (2011), as teorias em OP corroboram com o fato de que somente a aplicação de um instrumento psicológico, ou mesmo condução de técnicas isoladas, e muitas vezes descontextualizadas, não configuram um processo de OP. Para esses mesmos autores, em geral, o processo de OP é caracterizado por levantamento de demandas do(s) orientando(s) e, com base nessas, realizar intervenções visando atingir determinados objetivos, como promover autoconhecimento, conscientizar acerca da escolha profissional, dentre outros.

Nessa mesma direção, e apoiado nas constatações de escassez de estudos com essa proposta, obtidas na Tabela 1, torna-se importante analisar o que os pesquisadores nacionais têm produzido em termos de intervenções em OP nas escolas públicas nacionais. Em acréscimo, é relevante as argumentações de Souza, Menandro, Bertollo e Rolke (2009), as quais afirmam que a inserção da OP nas escolas públicas poderia fornecer oportunidades de os estudantes discutirem a sociedade e os significados da escolha profissional, o que os prepararia para uma entrada mais crítica e consciente no mundo do trabalho. Desse modo, a orientação caminharia na direção de contribuir para questionar informações estereotipadas sobre as profissões, para fornecer dados mais reais sobre os diversos contextos de trabalho e para refletir sobre os determinantes 
concretos das escolhas. Isto posto, o presente estudo objetivou apresentar uma revisão narrativa de artigos nacionais que tiveram como objetivo realizar intervenções grupais em OP com alunos matriculados no ensino regular em escolas públicas.

\section{MÉTODO}

\section{Fontes e Procedimentos}

A revisão foi feita nas bases de dados Scielo e Pepsic, cuja organização em quatro etapas está descrita a seguir e ilustrada na Figura 1.

Etapa 1- Foram feitas buscas nas bases de dados utilizando-se das palavras-chave "orientação vocacional" e "orientação profissional", que deveriam estar presentes no corpo do texto, sem restrição de ano de publicação. A busca pelos artigos na Scielo e na Pepsic foi realizada em junho de 2016.

Etapa 2 - Em seguida, foi feita a leitura dos títulos e dos resumos para verificar se os estudos se enquadravam no escopo de análise (processos de intervenção grupal em OP com pelo menos um orientando proveniente de escola pública). Os critérios de exclusão foram: artigos de revisão; artigos teóricos; pesquisas descrevendo processos de construção e estudos de qualidades psicométricas de instrumentos; manuscritos que não possuíam processo de intervenção em OP com estudantes do ensino regular de escolas públicas; e estudos que não continham a descrição detalhada das sessões de intervenção em OP.

Etapa 3 - Após a etapa 2, foi adotado o seguinte procedimento: verificação de possíveis sobreposições dos artigos dentro de uma mesma base de dados e entre as duas bases de dados (Scielo e Pepsic).

Etapa 4 - Em continuidade, foi feita a leitura do método dos artigos, em específico, a descrição dos participantes, devido ao fato de que em muitos resumos não ficou explícito se os mesmos eram oriundos de escolas públicas ou privadas.

Etapa 5 - Por fim, foi realizada a leitura na íntegra dos artigos selecionados para posterior descrição detalhada dos objetivos, participantes, procedimentos e resultados dos artigos selecionados. 


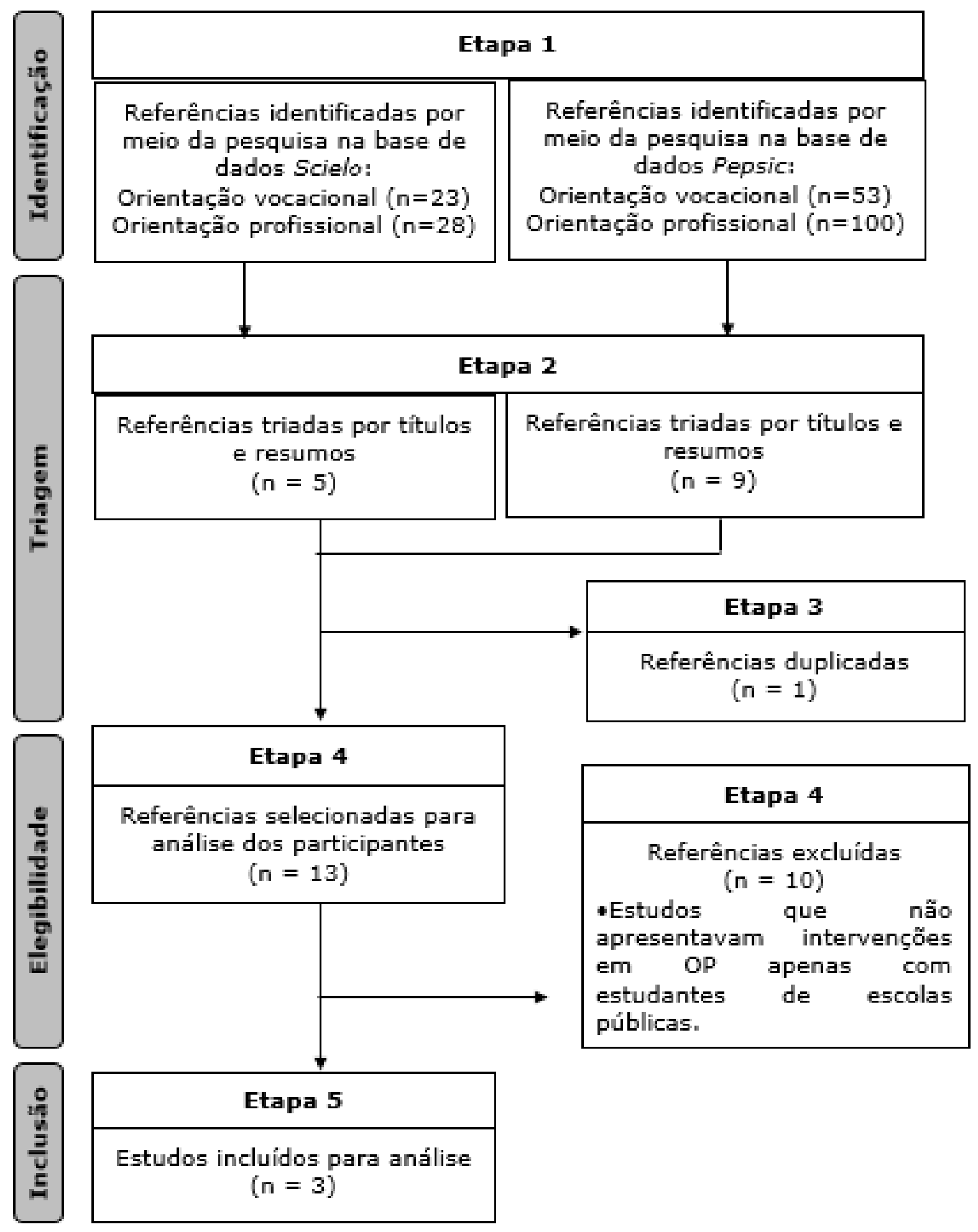

Figura 1. Fluxograma de seleção de revisão narrativa.

\section{RESULTADOS E DISCUSSÕES}

De acordo com os critérios de exclusão adotados na segunda e quarta etapa, estudos que objetivaram realizar uma revisão de literatura (ex. Abade, 2005; Rueda, 2009), artigos teóricos (ex. Canedo, 1997; Ambiel, 2014), pesquisas descrevendo processos de construção e estudos das qualidades 
psicométricas de instrumentos (ex. Primi, Moggi, \& Casellato, 2004; Godoy \& Noronha, 2010) e aqueles que não possuíam processo de intervenção em OP com estudantes do ensino regular em escola pública, ou seja, continham participantes de escola particular ou de escola técnica (ex. Oliveira \& Neiva, 2013), não foram incluídos na análise final.

Os artigos selecionados para a realização da leitura na íntegra, segundo a quinta etapa, estão expostos na Tabela 2. Tais estudos serão descritos no que tange a metodologia, procedimentos, participantes, processo de OP, e principais resultados encontrados.

Tabela 2. Estudos selecionados para leitura na íntegra.

\begin{tabular}{|c|c|c|c|}
\hline Autores & Ano de publicação & Revista & $\begin{array}{l}\text { Título da } \\
\text { publicação }\end{array}$ \\
\hline $\begin{array}{l}\text { Aguiar e } \\
\text { Conceição }\end{array}$ & 2008 & $\begin{array}{c}\text { Revista Brasileira } \\
\text { de Orientação } \\
\text { Profissional }\end{array}$ & $\begin{array}{l}\text { A orientação } \\
\text { vocacional na } \\
\text { perspectiva neo- } \\
\text { reichiana: } \\
\text { contribuições do } \\
\text { grounding }\end{array}$ \\
\hline Souza et al. & 2009 & $\begin{array}{l}\text { Psicologia Ciência } \\
\text { e Profissão }\end{array}$ & $\begin{array}{l}\text { Oficina de } \\
\text { orientação } \\
\text { profissional em } \\
\text { uma escola } \\
\text { pública: uma } \\
\text { abordagem } \\
\text { psicossocial }\end{array}$ \\
\hline Becker et al. & 2012 & $\begin{array}{c}\text { Revista Brasileira } \\
\text { de Orientação } \\
\text { Profissional }\end{array}$ & $\begin{array}{l}\text { Meu lugar no } \\
\text { mundo: relato de } \\
\text { experiência com } \\
\text { jovens em } \\
\text { orientação } \\
\text { profissional }\end{array}$ \\
\hline
\end{tabular}

O estudo de Aguiar e Conceição (2008), teve por objetivo apresentar os resultados colhidos em um trabalho de OP em grupo em que foi utilizado o exercício corporal neo-reichiano, baseado nos referenciais corporais das teorias neo-reichianas, como ferramenta de atuação terapêutica e as possíveis contribuições dessa utilização. As oficinas foram realizadas semanalmente, com duas horas de duração, em uma escola pública, no turno contrário ao das aulas regulares dos participantes, totalizando 10 encontros. Os participantes eram jovens entre 16 e 17 anos, sendo nove do sexo feminino e um do sexo masculino, do $3^{\circ}$ ano do ensino médio.

Havia uma mesma estrutura para todas as oficinas. Primeiro realizava-se uma conversa inicial sobre os acontecimentos da semana, principalmente ligados ao tema da escolha da profissão; em seguida, eram feitos exercícios corporais bioenergéticos relacionados ao aumento de autoexpressão e fortalecimento da identidade. Em continuidade realizava-se as atividades previstas para a oficina 
em questão. Por fim, havia um momento de compartilhamento, que consistia em conversar um pouco sobre o que cada um havia vivenciado com os exercícios e as atividades. De maneira geral, os temas trabalhados durantes os 10 encontros foram: interiorização e fortalecer grounding, coleta de informações, família, questionar valores, associar interesse e profissões, materializar a escola, e experimentar a escolha.

O resultado apontou que na maioria dos casos, os adolescentes estavam dominados por sentimentos de angústia e ansiedade diante da necessidade de escolher, refletindo no corpo (respiração alta e frequentemente acelerada, bloqueio diafragmático, entre outros). A falta de informação sobre o mundo profissional foi considerada uma das principais fragilidades dos grupos. Não obstante, os jovens apresentaram, na relação com seus familiares, dificuldade em assumir a escolha e estabelecer limites para o desejo dos pais. Essa condição também foi considerada uma fragilidade do grupo. O programa se mostrou efetivo uma vez que, de acordo com os autores, alguns adolescentes, mesmo sem terem tomado decisão, ficaram cientes de novas possibilidades profissionais que haviam surgido após o trabalho realizado, além de possíveis contribuições do trabalho com o corpo e das teorias neo-reichianas.

O estudo de Souza et al. (2009), descreveu uma intervenção em OP no formato de oficina realizada em uma escola pública de ensino médio (Vitória/ES). O objetivo da pesquisa foi contribuir com o debate sobre algumas possibilidades da OP realizada em grupos e no âmbito da educação pública. Participaram do estudo, inicialmente, 11 estudantes do $3^{\circ}$ ano (17 a 20 anos, sendo um de 33 anos), quatro do sexo masculino e sete do sexo feminino.

Foi conduzida em oito encontros, semanais, com duração de duas horas cada e utilizando do enfoque psicossocial. No primeiro encontro, realizaram-se técnicas em grupo para apresentação dos participantes e para colher informações sobre as expectativas quanto à oficina e ao futuro profissional. Nos encontros posteriores foram realizados debates sobre o cotidiano escolar, o que significa ter sucesso no futuro pessoal e profissional, sobre a liberdade de escolha, entre outras questões, de modo em que fosse possível uma análise capaz de deslocar a ênfase dada ao modelo de sucesso hegemônico, baseado na competição e no individualismo. Dessa forma, abriu-se a possibilidade de avaliação crítica de uma série de determinantes importantes para as decisões relativas ao futuro profissional, como a participação da escola, as relações interpessoais no trabalho, os direitos e deveres relacionados à cidadania e o papel social do trabalho, entre outros.

A partir do quinto encontro se iniciou discussões sobre as profissões. De acordo com Souza, et al. (2009), esse momento foi decisivo no que diz respeito ao debate das idealizações feitas em torno das diferentes profissões, pois se pode verificar que as idealizações se expressavam no desconhecimento de determinadas profissões. Nos últimos encontros, foram trazidas importantes 
reflexões sobre o mundo do trabalho, sobre os significados das escolhas profissionais, sobre os determinantes sociais, econômicos, familiares e pessoais dessas escolhas. O programa se mostrou efetivo uma vez que os estudantes relataram maior segurança frente aos planos de futuro e à escolha profissional e avaliaram positivamente a oficina proposta.

O estudo de Becker, Bobato e Schulz (2012) objetivou apresentar um relato de experiência referente a um projeto de OP desenvolvido em parceria com uma empresa de grande porte do ramo alimentício do estado de Santa Catarina, projeto este embasado pelo referencial teórico da abordagem sóciohistórica. Participaram nove adolescentes (entre 14 e 17 anos), filhos e dependentes dos trabalhadores da empresa, sendo quatro do sexo masculino e cinco do sexo feminino, estudantes entre o 90 ano do Ensino Fundamental e o $2^{\circ}$ ano do Ensino Médio, provenientes de escolas públicas.

Foram realizados sete encontros no período de dois meses, com duração de duas horas cada, sendo que no último encontro foi realizada uma avaliação de todo processo. Para o desenvolvimento dos encontros foram utilizadas técnicas grupais, relatos orais e relatos escritos. O projeto foi dividido em três módulos, sendo eles: Módulo 1, que contou com três encontros, visou trabalhar o autoconhecimento e projeto de vida (10- Apresentação do projeto, dos orientadores e participantes; estabelecimento do contrato grupal e levantamento de expectativas; 20 - Identidade, autoconhecimento, autoestima, interesses, habilidades, valores, modelos de identificação; $3^{\circ}$ - Projeto de vida). No Módulo 2, o quarto encontro, abordou os fatores que influenciam na escolha profissional. Já o Módulo 3, com dois encontros, trabalhou o conhecimento das profissões e do mercado de trabalho (50 - Estratégias para a inserção profissional, desenvolvimento de competências profissionais, critérios utilizados para a realização das escolhas, elaboração de currículo e entrevista de emprego; $6^{0}$ Demandas do mercado de trabalho, relato de profissionais convidados sobre sua trajetória profissional).

A avaliação do processo, sétimo encontro, foi feita a partir de um questionário semiestruturado, contendo questões sobre como os estudantes se sentiram ao participar dos encontros; atividades que menos gostaram e aquelas que foram mais significativas; o que faltou; e atendimento de expectativas. Entre os resultados obtidos têm-se que os participantes demonstraram expectativas positivas em relação ao futuro e à sua carreira profissional. Também relataram que o autoconhecimento foi prevalecente, pois permitiu que pensassem sobre seus projetos de vida e habilidades. Sobre o apoio e expectativa que os familiares nutrem em relação às escolhas na área profissional, todos os participantes se manifestaram de forma positiva, além de citarem influências da mídia, professores, profissionais qualificados e amigos. 
Dada a breve exposição sobre os artigos que se enquadravam nos critérios de análise do presente estudo, é possível observar alguns aspectos convergentes e outros divergentes, conforme exposto na Tabela 3.

Tabela 3. Síntese das informações obtidas por meio da análise dos artigos.

\begin{tabular}{lccc}
\hline \multirow{2}{*}{$\begin{array}{c}\text { Características do } \\
\text { estudo }\end{array}$} & Aguiar e & Referência \\
& Conceição (2008) & $(2009)$ & $\begin{array}{c}\text { Becker et al. } \\
(2012)\end{array}$ \\
\hline Local & Distrito Federal & Espírito Santo & Santa Catarina \\
Participantes (N) & 10 & 11 & 9 \\
Idade & 16 e 17 & 17 a 20 e um de & 14 e 17 \\
Sexo & $1 \mathrm{M} ; 9 \mathrm{~F}$ & $43 \mathrm{M} ; 7 \mathrm{~F}$ & $4 \mathrm{M} ; 5 \mathrm{~F}$ \\
Escolaridade & 30 ano EM & 30 ano EM & 90 ano EF e 20 \\
& & & ano EM \\
No de encontros & 10 & 8 & 7 \\
Duração & $2 \mathrm{~h}$ & $2 \mathrm{~h}$ & $2 \mathrm{~h}$ \\
Divisões & Sem divisão & Sem divisão & 3 módulos \\
Referencial teórico & Neo-reichiano & Sócio-histórico & Sócio-histórico \\
\hline Nota. M (masculino); F (feminino); EF (ensino fundamental); EM (ensino médio).
\end{tabular}

Entre os aspectos em comum pode-se citar que, em todas as pesquisas as sessões possuíam duas horas de duração e o número total de encontros não variou muito, de sete (Becker et al., 2012) a, no máximo, 10 encontros (Aguiar \& Conceição, 2008). Outros aspectos que também não tiveram grandes divergências foram em relação ao número inicial de participantes nos grupos de intervenção, entre nove (Becker et al., 2012) e 11 (Souza et al., 2009); a idade, já haviam jovens de 14 (Becker et al., 2012) a 20 anos (Souza et al., 2009); e, por fim, ao ano em que os alunos estavam matriculados, exceto um estudo que continha participantes do nono ano do ensino fundamental (Becker et al., 2012), os demais possuíam alunos do segundo e/ou terceiro ano do Ensino Médio. Em todos os estudos também havia um número superior de participantes do sexo feminino em relação ao sexo masculino.

Em relação ao conteúdo trabalhado nos encontros, os estudos possuem várias semelhanças, diferenciando mais em relação às técnicas empregadas. Os temas trabalhados, de modo geral, foram sobre autoconhecimento, informações sobre mercado de trabalho e profissões, tomada de decisões, influências e valores implicados na escolha profissional e projeto de vida. $O$ estudo de Aguiar e Conceição (2008) teve variações devido às diferenciações na forma de trabalho, focando em exercícios corporais neo-reichianas. Contudo, seus conteúdos se assemelham aos dos outros estudos. Não foi utilizado nenhum teste ou questionário que dialogue com teorias classificatórias, ao contrário, 
foram utilizados questionários, entrevistas e outros instrumentos como medida pré e/ou pós-intervenção.

Em relação às divergências entre os artigos analisados, tem-se que em Becker et al. (2012) a intervenção foi dividida em três fases ou módulos, enquanto os outros dois estudos não relataram tal divisão (Aguiar \& Conceição, 2008; Souza et al., 2009). É válido apontar, também, que cada investigação foi conduzida em um Estado diferente, como Santa Catarina, Espírito Santo e Distrito Federal. Essa diversidade seria interessante para levantar e analisar quais as principais demandas dos orientandos em diferentes regiões do Brasil e diversos grupos sociais. De acordo com Ribeiro (2003), "forneceria subsídios para a descrição dos modos de construção e desenvolvimento de projetos de vida profissional dos brasileiros, bem como para a elaboração de novas estratégias de ação" (p. 149).

Foi possível observar duas abordagens teóricas que foram utilizadas para a intervenção em OP, como a sócio histórica (Souza et al., 2009; Becker et al., 2012) e teoria neo-rechiana (Aguiar \& Conceição, 2008). Isso vem a contribuir ainda mais com a prática de $\mathrm{OP}$, uma vez que se permite uma ampliação nos olhares sobre esse processo, explorando outras dimensões dos indivíduos e seus determinantes.

A OP vem sendo oferecida hoje para os mais diversos públicos e em diferentes estados e cidades. A pequena quantidade de artigos encontrados no presente estudo, que se encaixavam nos critérios adotados, ou seja, que descreviam detalhadamente os processos de intervenção com alunos matriculados no ensino regular de escolas públicas, vai de encontro à fala de Ribeiro (2003), de que se tem a necessidade de mais pesquisas, teorias e modelos que correspondam à realidade de escolas públicas, uma vez que tais pesquisas poderiam apontar novos rumos a serem tomados pela OP.

\section{CONSIDERAÇÕES FINAIS}

O objetivo do presente estudo foi apresentar uma revisão narrativa de artigos nacionais que realizaram intervenções grupais em OP e que contivessem alunos matriculados no ensino regular em escola pública. Considera-se que o objetivo proposto fora alcançado uma vez que foram localizados, na literatura nacional, artigos e procedeu-se uma análise detalhada dos mesmos.

Tendo em vista o baixo número de artigos encontrados, é necessário que os profissionais de OP se atentem para o atendimento de estudantes sem priorizar a característica da instituição de ensino, ou seja, escolas públicas ou privadas. Futuros estudos podem considerar os artigos excluídos da análise no presente trabalho para averiguar se, por exemplo, em pesquisas com outros objetivos que não o de intervenção, há mais participação de alunos matriculados no ensino regular da rede pública. Não obstante, pesquisas que ampliem as 
bases de dados também podem vir a contribuir, de modo a comparar programas feitos em escolas púbicas e privadas, assim como analisar suas demandas objetivando contribuir para o desenvolvimento da OP no cenário nacional. Nessa mesma direção, também podem ser realizadas pesquisas que incluam a literatura internacional e comparem com o panorama nacional.

\section{DECLARAÇÃO DE CONFLITOS DE INTERESSE}

Não há conflitos de interesse.

\section{REFERÊNCIAS}

Abade, F. L. (2005). Orientação profissional no Brasil: Uma revisão histórica da produção científica. Revista Brasileira de Orientação Profissional, 6(1), 1524. Recuperado de http://pepsic.bvsalud.org/pdf/rbop/v6n1/v6n1a03.pdf.

Aguiar, F. H. R., \& Conceição, M. I. G. (2008). A orientação vocacional na perspectiva neo-reichiana: Contribuições do grounding. Revista Brasileira de Orientação Profissional, 9(1), 115-128. Recuperado de http://pepsic.bvsalud.org/pdf/rbop/v9n1/v9n1a10.pdf.

Aguiar, F. H. R., \& Conceição, M. I. G. (2012). Análise da produção científica em orientação profissional: Tendências e velhos problemas. Psico-USF, 17(1), 97-107. http://dx.doi.org/10.1590/S1413-82712012000100011

Ambiel, R. A. M. (2014). Adaptabilidade de carreira: uma abordagem histórica de conceitos, modelos e teorias. Revista Brasileira de Orientação Profissional, 15(1), 15-24. Recuperado de http://pepsic.bvsalud.org/pdf/rbop/v15n1/04.pdf.

Ambiel, R. A. M., Lamas, K. C. A., \& Melo-Silva, L. L. (2016). Avaliação dos interesses profissionais no Brasil: Revisão da produção científica. Avaliação Psicológica, 15(no especial), 1-9. Recuperado de http://pepsic.bvsalud.org/pdf/avp/v15nspe/v15nspea02.pdf.

Ambiel, R. A. M., \& Polli, M. F. (2011). Análise da produção científica brasileira sobre avaliação psicológica em orientação profissional. Estudos Interdisciplinares em Psicologia, 2(1), 103-121. http://dx.doi.org/10.5433/2236-6407.2011v2n1p103

Bastos, J. C. (2005). Efetivação de escolhas profissionais de jovens oriundos do ensino público: Um olhar sobre suas trajetórias. Revista Brasileira de Orientação Profissional, 6(2), 31-43. Recuperado de http://pepsic.bvsalud.org/pdf/rbop/v6n2/v6n2a04.pdf.

Becker, A. P. S., Bobato, S. T., \& Schulz, M. J. L. C. (2012). Meu lugar no mundo: Relato de experiência com jovens em orientação profissional. Revista Brasileira de Orientação Profissional, 13(2), 253-263. Recuperado de http://pepsic.bvsalud.org/pdf/rbop/v13n2/12.pdf. 
Bock, S. D. (2002). Orientação profissional: A abordagem sócio-histórica. Cortez Editora.

Canedo, I. R. (1997). Contribuições da Gestalt-Terapia para o referencial teórico da Orientação Profissional. Revista da $A B O P, 1(1)$, 59-67. Recuperado de http://pepsic.bvsalud.org/pdf/rabop/v1n1/v1n1a05.pdf.

Faht, B. H. (2011). Fatores que influenciam a escolha profissional do jovem universitário e sua visão a respeito da orientação profissional. (Dissertação de mestrado). Univali: Itajaí/SC.

Godoy, S., \& Noronha, A. P. P. (2010). Estudo correlacional entre a Escala de Aconselhamento Profissional (EAP) e o Inventário Fatorial de Personalidade (IFP). Estudos e Pesquisas em Psicologia, 10(3), 848-864. Recuperado de http://pepsic.bvsalud.org/pdf/epp/v10n3/v10n3a13.pdf.

Lassance, M. C., \& Sparta, M. (2003). A orientação profissional e as transformações no mundo do trabalho. Revista Brasileira de Orientação Profissional, 4(1/2), 13-19. Recuperado de http://pepsic.bvsalud.org/pdf/rbop/v4n1-2/v4n1-2a03.pdf.

Melo-Silva, L. L., Leal, M. S., \& Fracalozzi, N. M. N. (2010). Produção científica em congressos brasileiros de orientação vocacional e profissional: Período 1999-2009. Revista Brasileira de Orientação Profissional, 11(1), 107-120. Recuperado de http://pepsic.bvsalud.org/pdf/rbop/v11n1/v11n1a11.pdf.

Noronha, A. P. P., \& Ambiel, R. A. M. (2006). Orientação profissional e vocacional: Análise da produção científica. Psico-USF, 11(1), 75-84. http://dx.doi.org/10.1590/S1413-82712006000100009

Noronha, A. P. P., Ventura, C. D., Cecilio-Fernandes, D., Nery, J. C. S., Bueno, J. D. P., Luca, L., \& Silva, M. A. P. (2014). Análise de Produções da Revista Brasileira de Orientação Profissional. Psico, 45(1), 26-34. http://dx.doi.org/10.15448/1980-8623.2014.1.12416

Oliveira, M. R., \& Neiva, K. M. C. (2013). Orientação vocacional/profissional: Avaliação de um projeto piloto para estudantes da educação profissional. Revista Brasileira de Orientação Profissional, 14(1), 133-143. Recuperado de http://pepsic.bvsalud.org/pdf/rbop/v14n1/13.pdf.

Pocinho, M. D., Correia, A., Carvalho, R. G., \& Silva, C. (2010). Influência do gênero, da família e dos serviços de psicologia e orientação na tomada de decisão de carreira. Revista Brasileira de Orientação Profissional, 11(2), 201-212. Recuperado

de http://pepsic.bvsalud.org/pdf/rbop/v11n2/v11n2a05.pdf.

Primi, R., Moggi, M. A., \& Casellato, E. O. (2004). Estudo correlacional do inventário de busca auto dirigida (self-directed search) com o IFP. Psicologia Escolar e Educacional, 8(1), 47-54. Recuperado de http://pepsic.bvsalud.org/pdf/pee/v8n1/v8n1a06.pdf. 
Ribeiro, M. A. (2003). Demandas em orientação profissional: Um estudo exploratório em escolas públicas. Revista Brasileira de Orientação Profissional, 4(1/2), 141-151. Recuperado de http://pepsic.bvsalud.org/pdf/rbop/v4n1-2/v4n1-2a12.pdf.

Ribeiro, M. A., \& Melo-Silva, L. L. (2011). Compêndio de orientação profissional e de carreira: Perspectivas históricas e enfoques teóricos clássicos e modernos. (Vol. 1). São Paulo, SP: Vetor.

Rueda, F. J. M. (2009). Produção científica da Revista Brasileira de Orientação Profissional. Revista Brasileira de Orientação Profissional, 10(2), 129-139. Recuperado de http://pepsic.bvsalud.org/pdf/rbop/v10n2/v10n2a13.pdf.

Silva, J. E., Fuzaro, C. M., \& Pacheco, M. M. D. R. (2016). A escolha profissional para adolescentes: Panorama de estudos e pesquisas. Revista Magistro, 1(13), 170-185. Recuperado de http://publicacoes.unigranrio.edu.br/index.php/magistro/article/view/3092/ 2081.

Silva, C. D., Vieira, N. G. C., Cardoso, H. F., \& Campos, D. C. (2015). Orientação profissional em cursinhos populares: Uma revisão acerca dos estudos brasileiros. Revista Sul Americana de Psicologia, 3(1), 138-155. Recuperado de http://www.revista.unisal.br/am/index.php/psico/article/view/57/77.

Sparta, M. O. (2003). O desenvolvimento da orientação profissional no Brasil. Revista Brasileira de Orientação Profissional, 4(1), 1-11. Recuperado de http://pepsic.bvsalud.org/pdf/rbop/v4n1-2/v4n1-2a02.pdf.

Souza, L. G. S., Menandro, M. C. S., Bortollo, M., \& Rolke, R. K. (2009). Oficina de orientação profissional em uma escola pública: Uma abordagem psicossocial. Psicologia Ciência e Profissão, 29(2), 416-427. Recuperado de http://pepsic.bvsalud.org/pdf/pcp/v29n2/v29n2a16.pdf.

Teixeira, M. A. P., Lassance, M. C. P., Silva, B. M. B., \& Bardagi, M. P. (2007). Produção científica em orientação profissional: Uma análise na revista brasileira de orientação profissional. Revista Brasileira de Orientação Profissional, 8(2), 25-40. Recuperado de http://pepsic.bvsalud.org/pdf/rbop/v8n2/v8n2a04.pdf. 
Sobre os autores

Bruna Pessenda é psicóloga pela Universidade Estadual Paulista "Júlio de Mesquita Filho". bruna.ghia88@gmail.com

Thais de Souza Mascotti é psicóloga pela Universidade Estadual Paulista "Júlio de Mesquita Filho", mestranda do programa de pós-graduação em Psicologia da Universidade Estadual Paulista "Júlio de Mesquita Filho".

thaismascotti@gmail.com

Hugo Ferrari Cardoso é psicólogo pela Universidade Sagrado Coração, mestre, doutor e pós-doutor em Psicologia pela Universidade São Francisco, docente dos programas de graduação e pós-graduação em Psicologia da Universidade Estadual Paulista "Júlio de Mesquita Filho". hfcardoso@gmail.com

Certificamos que todos os autores participaram suficientemente do trabalho para tornar pública sua responsabilidade pelo conteúdo. A contribuição de cada autor pode ser atribuída como se segue: Bruna Pessenda, Thais de Souza Mascotti e Hugo Ferrari Cardoso contribuíram para a conceitualização, investigação e visualização do artigo; Bruna Pessenda e Thais de Souza Mascotti fizeram a redação inicial do artigo; Thais de Souza Mascotti e Hugo Ferrari Cardoso são os responsáveis pela redação final (revisão e edição).

Recebido em: 27/01/2017

Revisado em: 25/03/2017

Aceito em: 10/07/2017 